\title{
VESTIBOLOGY
}

\section{Analysis of the nystagmus evoked by cross-coupled acceleration (Coriolis phenomenon)}

\author{
Analisi del nistagmo evocato da accelerazione "cross-coupled" (fenomeno di Coriolis) \\ M. LUCERTINI' ${ }^{1}$, E. BIANCA ${ }^{1}$, E. MARCIANO ${ }^{2}$, V.E. PETTOROSSI ${ }^{3}$ \\ ${ }^{1}$ Italian Air Force, Flight Experimental Centre, Aerospace Medicine Department, Pomezia (Rome), Italy; ${ }^{2}$ Audiology \\ Section, Neuroscience Department, "Federico II" University, Naples, Italy; ${ }^{3}$ Experimental Medicine Department, \\ Perugia University, Perugia, Italy
}

\section{SUMMARY}

Motion sickness and spatial disorientation represent two outstanding challenges in aviation medicine. In both cases, the vestibular system plays a fundamental role in their genesis. One of the most common ground-based simulations utilised in aero-physiological training is the sense of vertigo and tilt generated by the cross-coupled stimulation of the semicircular canals, while exposed to rotation in the yaw axis (Coriolis' Phenomenon: CP). However, the complex stimulus induced on the two labyrinths by this manoeuvre still deserves investigation. Nine male subjects sitting on a rotatory chair were asked to tilt their head back and forth during a yaw - axis clock - (CW) or counterclock-wise $(\mathrm{CCW})$ rotation at a constant speed of $70 \% \mathrm{sec}$, generating the CP. Eye movements were recorded via Video-Oculo-Scopy and qualitatively analysed. A second camera simultaneously recorded the subject's and chair's movements. The observed nystagmus (Ny) was then analysed and related to the actual head/chair position and motion. A clear relationship was detected between Ny, head movements and direction of chair rotation. During CW rotation, backward head tilts systematically induced a CW-Ny, while a CCW-Ny was observed while returning to the upright position, or during forward head tilt. Opposite patterns were detected during CCW chair rotation. Minor lateral eye movements were also observed, due to the activity of horizontal semicircular canals, but no vertical ones. Due to the neural connections between extra-ocular muscles and each labyrinth sensor, the semicircular canals involved in the genesis of the Ny during this form of stimulation could be identified. In agreement with the third Ewald's law, our results indicated a dominant left labyrinth during backward tilt and $\mathrm{CW}$ motion, or forward tilt and CCW rotation. On the contrary, during forward tilt and CW rotation, or backward tilt and CCW rotation, the right vertical canals produced the main contribution to ocular response.

KEY WORDS: Motion sickness • Spatial disorientation • Vestibular system • Nausea and vomiting • Eye movements

\section{RIASSUNTO}

Le chinetosi e il disorientamento spaziale costituiscono due sfide di particolare rilievo in medicina aeronautica. In entrambi i casi, il sistema vestibolare svolge un ruolo determinante nella loro genesi. Una delle forme più comuni di simulazione a terra, impiegata nel corso dell'addestramento aerofisiologico degli equipaggi di volo, consiste nel senso di vertigine e inclinazione generato dalla stimolazione incrociata dei canali semicircolari durante una rotazione sull'asse verticale (yaw) con simultaneo movimento attivo della testa in pitch o in roll (cosiddetto fenomeno di Coriolis). Nonostante l'esistenza di pregressi studi, la complessità dello stimolo indotto da tale manovra sui due labirinti richiede ancora alcuni approfondimenti, come nel caso della stimolazione specifica dei singoli recettori labirintici e della seguente risposta oculomotoria. Nove soggetti di sesso maschile hanno partecipato allo studio, sottoponendosi a sedute su sedia rotatoria, durante le quali hanno inclinato attivamente il capo in avanti e indietro (i.e. solamente in pitch) nel corso di rotazioni della sedia in yaw sia in senso orario che antioratio, ad una velocità costante di $70 \%$ sec, generando il fenomeno di Coriolis. I movimenti oculari sono stati registrati attraverso Video-Oculo-Scopia e quindi analizzati. Una seconda videocamera registrava contemporaneamente i movimenti del soggetto e della sedia. Durante ogni manovra in pitch della testa, il soggetto riferiva inoltre la propria percezione soggettiva di movimento. Il nistagmo (Ny) registrato era poi messo in relazione al movimento del capo e della sedia. Un'evidente relazione è stata osservata tra direzione del Ny, movimenti del capo e senso di rotazione della sedia. Durante la rotazione della sedia in senso orario, l'inclinazione indietro del capo induceva sistematicamente un Ny rotatorio orario, mentre uno antiorario veniva osservato al ritorno in posizione verticale del capo, o nel caso di una sua flessione in avanti. Parametri opposti sono stati osservati durante la rotazione della sedia in senso antiorario. Minimi movimenti laterali degli occhi, legati all'attività dei canali semicircolari laterali, sono stati anche registrati, unitamente a una sostanziale assenza di movimenti verticali. Più eterogenee sono invece risultate le risposte riferite alla percezione soggettiva di movimento. A causa delle connessioni neurologiche tra sensori labirintici e muscolatura extraoculare, è stato possibile identificare $i$ canali semicircolari coinvolti nella genesi del Ny durante questo particolare tipo di stimolazione. In armonia con la terza legge di Ewald, i nostri risultati indicano un labirinto sinistro dominante durante la retroflessione del capo e la rotazione della sedia in senso orario, oppure durante l'anteroflessione del capo in corso di rotazione antioraria della sedia. Al contrario, durante l'anteroflessione del capo in corso di rotazione oraria della sedia, oppure durante la sua retroflessione durante una rotazione antioraria, sono i canali verticali del lato destro a fornire il maggiore contributo alla risposta oculomotoria. I nostri dati indicano inoltre un'elevata variabilità interindividuale nella percezione soggettiva di movimento durante tale tipologia di manovre. 


\section{Introduction}

Motion sickness (MS) and spatial disorientation (SD) represent two outstanding challenges in aviation medicine. In both cases, the vestibular system plays a fundamental role in the genesis of these phenomena ${ }^{1-5}$.

One of the most common ground-based simulations utilised in aviation medicine, reproducing within a laboratory setting some of the potential effects of an in-flight vestibular illusion along with a nauseogenic environment, is the artificial sense of vertigo and tilt generated by the so-called cross-coupled stimulation of the semicircular canals from the two labyrinths, during the exposure to an on-axis yaw rotation on a standard rotatory chair ${ }^{6}$.

During these exercises, the subject tilts his/her head back or forth (pitch), or on one side (roll), while passively rotating, and this movement generates a sudden change in the direction of the rotatory acceleration acting on the cupulae, along with a variation in the direction of the gravito-inertial force acting on the otoliths. In unadapted individuals, this particular type of vestibular stimulation, if performed during a sufficiently high speed of chair rotation (i.e. $\geq 50-60^{\circ} / \mathrm{sec}$ ), easily provokes a strong sense of vertigo with nystagmus ( $\mathrm{Ny}$ ), and if the manoeuvre is repeated several times, an evident neurovegetative response, when sweating, pallor, nausea, or even vomiting, occurs. In aviation medicine, these effects are usually identified as Coriolis' phenomenon (CP), although the acceleration forces involved in labyrinth fluid displacement are different from those reported by Gustave Gaspar de Coriolis in the early nineteenth century ${ }^{7}$. As a matter of fact, the genuine Coriolis' acceleration $a$ is that experienced by a body which linearly moves at a velocity $v$ while exposed to rotation at a speed $\omega$ about an orthogonal axis with respect to the body linear movement, so that $a=2 v \omega$.

In the animal model, the ocular response to this acceleration was investigated by Maruta et al. ${ }^{8}$, who observed different vestibulo-ocular reflexes secondary to translation while rotating, depending on the direction of the acceleration with respect to the head, and to the frequency of the linear component.

Therefore, in this experimental setting, no additional rotational forces are experienced except for the rotating platform, which is not the case for the CP normally evoked in humans during SD training or MS evaluation and treatment, where pitch and/or roll head movements are also made 5910 .

Although the clinical findings related to the genesis of the $\mathrm{CP}$ are well documented in the literature ${ }^{356910}$, only a few studies tried to focus attention on the human vestibular physiology underlying such a very particular form of stimulation, during ${ }^{11}{ }^{12}$, or immediately after rotation (so-called Purkinje effect) ${ }^{11}{ }^{13}$. More in detail, some authors analysed the impact of $\mathrm{CP}$ on body sway, ocular movements, and subjective perception ${ }^{12}$, although they limited their analysis to the sole recording of eye movements, without examining its probable source at the vestibular end organs ${ }^{14}$. Therefore, the analysis of the peripheral genesis of ocular motion in the $\mathrm{CP}$-related head movements (i.e. during passive clockand anti-clock-wise body rotation in the yaw axis) may still require some further contribution. Such head movements induce a bilateral stimulus on the two labyrinths, in its turn producing specific eye movements, due to the strict interrelation existing between vestibular sensors stimulation and oculomotor response, and to the dominant vestibular input, as reported in Ewald's laws ${ }^{15}$. The rotatory component of the $\mathrm{CP}$-induced nystagmus might be a useful contributing factor in detecting the dominant labyrinth, due to its neurophysiological links with each crista ampullaris. In many cases, such analysis could not be performed in the past with the use of electrophysiological recordings of eye movements as they are not able to report ocular rolling ${ }^{16}$.

More recently, the use of the video-oculo-scopic techniques (VOS) has significantly improved the capability of detecting those torsional components of eye movements that represent part of the final output of a stimulus involving the cupolae of the two vertical canals connected to the superior and the inferior oblique muscles, and so produce as a primary action the intorsion or the extorsion of the eyeball ${ }^{14}{ }^{17}$. Therefore, the VOS significantly increases the capability of analysing these details of eye movements during the execution of CP related head tilts. Thus, the aim of this study was the VOS analysis of normal subjects during both forward and backward head tilts while undergoing an on-vertical axis rotation on a rotatory chair, identifying those semicircular canals mainly contributing to the genesis of the $\mathrm{CP}$, and to the related perception.

\section{Materials and methods}

Our data were collected at the Aerospace Medicine Department of the Italian Air Force Flight Experimental Centre. The research was approved by the local Ethics Committee, and was in agreement with the Helsinki Declaration.

Our sample consisted of nine male volunteers (mean age $26 \pm 4$ years), forming part of the aircrew members undergoing standard aerophysiological training, according to the current NATO STANAG $3114{ }^{18}$. Each subject re- 
sulted normal in past medical checks, and certified as fit for flying duties at one of the Italian Air Force Institutes of Aerospace Medicine, where screening for vestibular disorders is also conducted.

All individuals were seated on a rotatory chair, wearing VOS devices with monocular recording of the right eye (Synapsys infrared videocamera, with a sample rate of $48 \mathrm{~Hz}$ ), connected to a wireless camera battery pack, which was secured on the subject's right arm via an elastic band (Fig. 1). All subjects were asked to keep their eyes open during each test session, in order to easily record eye movements (monitored by the operator via a video-recording system). Visual fixation was inhibited by the dark visual environment generated by the VOS mask (Fig. 1). The VOS signal was then transferred to a wireless receiver, and then to a multichannel digital video recorder. All data was stored and analysed in an off-line mode by a computerised system. During the test session, eye movements could be observed on a screen connected to the VOS videocamera. A second camera (IR digital CCD videocamera) simultaneously recorded the chair and the subject's movements and was connected to the same vid-

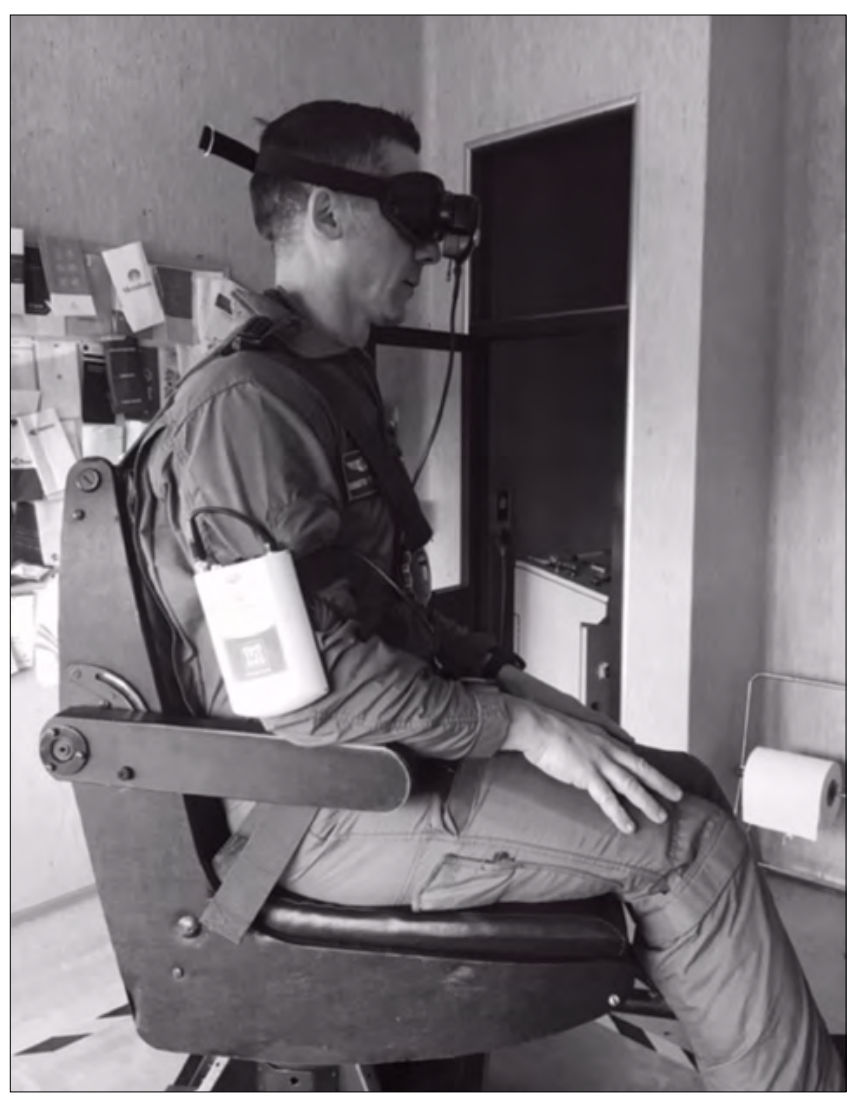

Fig. 1. Subject sitting in upright position on the rotatory chair, wearing the VOS mask and wireless camera battery pack on his right arm. eo-recorder so that the subject's head position and movement could be easily coupled with the corresponding eye movement.

Each subject randomly underwent both a clockwise $(\mathrm{CW})$ and a counter-clockwise (CCW) session of rotations at a constant speed of $70 \% \mathrm{sec}$, lasting for a total of roughly 10 minutes. After rotation began, once the target speed was reached, each individual maintained an upright position for a few tens of seconds so as to obtain a complete fading of the subjective perception of rotation and of the rotation-induced eye movements (detected via the VOS recording). The individual was then asked to actively rotate his head back or forth (pitch rotation), according to a random sequence that systematically included:

1. a pitch-up movement (i.e. backward tilt), followed by a return to the upright position;

2. a pitch-down movement (i.e. forward tilt), with subsequent return to the upright position.

Therefore, in this experiment, only data from pitch-head movements during passive body rotation in the yaw axis were considered (i.e. no responses from roll-head movements were obtained). Each movement started exclusively after the complete fading of symptoms (sense of rotation and/or movement) and Ny evoked by the previous manoeuvre (observed via the on-line VOS recording).

Throughout each test session, the Ny evoked by each manoeuvre was recorded, along with the chair and subject's movements, and with the perception and/or symptoms reported by each individual (these were related to the perceived sense of rotation and/or tilt, along with the onset of MS related symptoms).

Due to the aim of this research, the following parameters were analysed for each subject:

1. direction of chair rotation (i.e. $\mathrm{CW}$ or $\mathrm{CCW}$ );

2. type of head movement performed (i.e. backward tilt, back to upright from backward tilt, forward tilt, back to upright from forward tilt);

3. presence/absence of a Ny evoked by these manoeuvres;

4. direction of the evoked $\mathrm{Ny}$;

5. presence/absence of a concurrent change in the subjective sense of orientation (as reported by the subject).

A calculus of the peripheral sensors (i.e. the cristae ampullarum of the semicircular canals) generating those specific eye movements was then performed. As usual, the direction of the $\mathrm{Ny}$ was diagnosed according to its fast phase, which means that the vestibular component was in the opposite direction (i.e. slow phase). Fast torsional components were denoted as a $\mathrm{CW}$ or $\mathrm{CCW} \mathrm{Ny}$, as observed by the investigator's side (i.e. not by the subject's one). 


\section{Results}

All subjects were able to perform the entire experimental session, consisting in the VOS recording under eight different test conditions (i.e. backward tilt, back to upright from backward tilt, forward tilt, back to upright from forward tilt; all of these repeated for both $\mathrm{CW}$ and $\mathrm{CCW}$ chair rotation), without the need to interrupt the test session due to the onset of nauseogenic vertigo. During all these test conditions, a clear oculomotor response was detected in all subjects.

In every case, the VOS showed small and irregular horizontal components of eye motion, while an evident $\mathrm{CW}$ or CCW Ny was also detected. No evident vertical ocular movements were detected during the majority of test sessions.

\section{Results for $C W$ chair rotation}

The backward head tilt systematically produced a torsional $\mathrm{CW} \mathrm{Ny}$, indicating a left vestibular dominance of the two vertical canals (i.e. anterior and posterior). On the contrary, during the return to the upright position, a CCW nystagmus was observed (i.e. dominance of right vertical canals). During these manoeuvres, a sense of pitch up during backward tilt and of pitch down on return to upright was usually experienced, although not in all cases (i.e. 5 of 9 individuals: $56 \%$ ).

During forward head tilt, opposite VOS findings were observed in all cases (i.e. a CCW Ny indicating dominant right vertical canals), and a CW Ny at the return to the upright position (i.e. dominance of left vertical canals). Even in this case, symptoms were not uniform among individuals, with the most represented consisting of a perception of pitch down during the tilt ( $67 \%$ of cases), and of right roll at the return to upright (7 out of 9 individuals: $78 \%$ ). These results are summarised in Table Ia.

\section{Results for CCW chair rotation}

In CCW chair rotation a constant type of oculomotor responses was observed, resulting in being of opposite direction with respect to those recorded during $\mathrm{CW}$ chair rotation, with a CCW Ny during backward tilt (i.e. right dominant labyrinth), a CW Ny at the return to upright (i.e. left dominant labyrinth), a CW Ny at the forward tilt (i.e. left dominant labyrinth), and a CCW Ny at the return to upright from forward tilt (i.e. right dominant labyrinth). As to the sensation during such manoeuvres, this was mainly represented by a sense of pitch up during backward tilt (56\% of cases) vs a sense of pitch down at the return to upright (44\% of cases). For forward tilts, in 4 subjects (44\% of total sample) a sensation of pitch down was usually experienced, with a sense of rolling to the right at the return to upright. The results from $\mathrm{CCW}$ chair rotation are summarised in Table Ib.

\section{Discussion}

The main finding of this study is represented by the constant and uniform type of oculomotor response observed in the entire sample, contrasting with a high interindividual variation in the sense of orientation. This is not a new finding, since a discrepancy between stimulus profile, oculomotor response and movement perception has already been reported in several publications focusing on this particular behaviour of the vestibular system, especially in the presence of complex motion ${ }^{19-21}$.

In our case, the total response observed from the two labyrinths during for- and/or back-ward tilt is in agreement with Ewald's third law, asserting that the ampullofugal (i.e. excitatory) endolymph flow in the vertical canals causes a greater response than the ampullopetal (i.e. inhibitory) one ${ }^{15}$, with an opposite direction of the Ny recorded during these two different stimuli. In both cases, a reverse of Ny direction was observed on return to upright, which indicates that the return movement, rather than the final position itself, mainly conditioned the vestibulo-ocular reflexes. In fact, for $\mathrm{CW}$ chair rotation, both a $\mathrm{CCW}$ and a CW Ny were observed in the same upright position, on return from backward and forward tilt respectively. Accordingly, opposite findings were detected during CCW chair rotation.

In our sample, the lateral canal contribution was not so

Table I. Direction of nystagmus and subjective sensation during CW (a) and CCW (b) chair rotation. The first column indicates the head movement evoking both the oculomotor response and the subjective illusion in the same row. While the oculomotor response resulted extremely constant within our sample (100\% of cases), the subjective sensation varied among individuals and only the most represented one is reported (prevalence in brackets).

\begin{tabular}{lcc} 
a. CW chair rotation & Ny direction & Subjective sensation \\
\hline $\begin{array}{l}\text { Backward head tilt } \\
\text { Upright from backward }\end{array}$ & CW & Pitch up (56\%) \\
Forward head tilt & CCW & Pitch down (56\%) \\
Upright from forward & CW & Pitch down (67\%) \\
b. CCW chair rotation & & Right roll (78\%) \\
& Ny direction & Subjective sensation \\
Backward head tilt & CCW & Pitch up (56\%) \\
Upright from backward & CW & Pitch down (44\%) \\
Forward head tilt & CW & Pitch down (44\%) \\
Upright from forward & CCW & Right roll (44\%) \\
\hline
\end{tabular}


evident, with the exception of per- and post-rotatory $\mathrm{Ny}$ with an upright subject at the beginning and end of each experimental session. During head tilt, this was possibly due either to a relatively mild stimulus involving the lateral canal and/or to a masking effect on the part of those eye roll movements induced by activation of the two vertical canals.

The lack of evident vertical components of eye movements is probably due to the simultaneous activation of both vertical canals from the same labyrinth (i.e. anterior and posterior). In this case, while a synergic roll movement is evoked on the eyeball from the two cupolae, a simultaneous input producing eye movements having opposite direction is generated by the same two sensors, acting on the extraocular muscles dedicated to up- and downward rotation of the eyeball (i.e. the superior and inferior rectus respectively), inhibiting each other ${ }^{14}$.

Our VOS findings are substantially identical to those observed in two subsequent studies by Takahashi et al. ${ }^{22}$ and by Watanuki et al. ${ }^{12}$, although in their case a constant subjective sensation was reported, with a sense of lateral sway that we did not observe except in a few cases (cfr. Table I). These data further confirm how, especially for complex and/or atypical stimulations, the cognitive response to vestibular input might result in a high intersubject variability.

Besides the absolute single subject's sensitivity to the CP, which is very variable, a careful and highly specific description of the subjective perception of such a brief illusory motion might be difficult to obtain and standardise in individuals who are not trained for this specific purpose, as in our sample. However, if past findings indicating the generation of illusory motion (or no-motion) during particular and complex vestibular stimulations are also considered ${ }^{19-21}{ }^{23}$, this might be an interesting topic for further research.

As to the vestibular side involved in the genesis of $\mathrm{CP}$, our data clearly indicate that during backward head tilt the left labyrinth plays the major role for $\mathrm{CW}$ rotation, while the right labyrinth is dominant for $\mathrm{CCW}$ rotation. Opposite findings can be observed in the case of forward head tilt, with a dominant right labyrinth if a $\mathrm{CW}$ rotation is performed, vs the left labyrinth under CCW chair rotation. In all cases, a rebound Ny having similar parameters, but opposite direction is detected at the return to the upright position.

Due to the high prevalence of vestibular related misperception in aircrew members, as well as in other categories of individuals exposed to moving environments, both in the case of MS as in that of SD events ${ }^{62-26}$, our findings might contribute to a better understanding of those sensory phenomena underlying the correct evaluation of different sensory cues, especially when particularly demanding tasks are required.

\section{Acknowledgements}

The authors wish to thank WO G. Angelino for his technical support during the different experimental steps. They are also thankful to Mrs. Diana Cook for her revision of the English text.

This study was planned and developed as part of the thesis for the graduation in medicine of author BE at Naples University "Federico II".

Part of the data from this study were presented at the 65th International Congress of Aviation and Space Medicine, Rome 10-14 September 2017.

\section{Conflict of interest statement}

None declared.

\section{References}

1 Bles W, Bos JE, de Graaf B, et al. Motion sickness: only one provocative conflict? Brain Res Bull 1998;47:481-7. https://doi. org/10.1016/s0361-9230(98)00115-4.

2 Cheung B. Non-visual spatial orientation mechanisms. In: Previc FH, Ercoline WR, editors. Spatial disorientation in aviation. Reston VA: AIAA; 2004. pp. 37-94.

3 Cheug B. Non-visual illusions in flight. In: Previc FH, Ercoline WR, editors. Spatial disorientation in aviation. Reston VA: AIAA; 2004. pp. 243-81.

4 Griffin MJ. Motion sickness. In: Handbook of Human Vibration. London (UK): Academic Press; 1990. pp. 271-332.

5 Lucertini M, Lugli V. The Italian Air Force rehabilitation programme for airsickness. Acta Otorhynolaryngol Ital 2004;24:181-7.

6 NATO-RTO-TR-HFM-118. Spatial disorientation training - demonstration and avoidance. Final Report of Task Group TG-039. 2008.

7 Coriolis de GG. Sur les équations du movement relatif des systèmes de corps. J de l'Ecole Royale Polytechnique 1835;15:144-54.

8 Maruta J, Simpson JI, Raphan T, et al. Orienting eye movements and nystagmus produced by translation while rotating (TWR). Exp Brain Res 2005;163:273-83. https://doi.org/10.1007/s00221-004-2178-5.

9 Bos JE, Bles W, de Graaf B. Vestibular adaptation in aviators: a longitudinal survey of vestibular parameters related to motion sickness in pilots of the Royal Netherlands Air Force. Soesterberg, The Netherlands: TNO Human Factors Report TM-00-A052; 2000.

10 Stott JRR. Adaptation to nauseogenic motion stimuli and its application in the treatment of airsickness. In: Crampton GH, editor. Motion and Space Sickness. Boca Raton, FL: CRC Press; 1990. pp. 373-90.

11 Meda E. Effetti di ripetuti eccitamenti rotatori dell'apparato vestibolare sui fenomeni soggettivi da cambiamento di posizione del capo durante e dopo rotazione. Riv Med Aer Spaz 1947;3:316-23.

12 Watanuki K, Takahashi M, Ikeda T. Perception of surrounding space controls posture, gaze, and sensation during Coriolis stimulation. Aviat Space Environ Med 2000;71:381-7.

13 Fetter M, Tweed D, Koenig E. The effect of head reorientation on the direction of postrotatory nystagmus in humans. In: d'Ydewalle G, Van 
Rensbergen J, editors. Visual and oculomotor functions. Advances in eye movement research. Amsterdam (NL): North-Holland Elsevier Science; 1994. pp. 399-405.

14 Leigh RJ, Zee DS. The neurology of eye movements. Third Edition. New York (NY): Contemporary Neurology Series; 1999.

15 Ewald R. Physiologische unt er suchunmgen über das endorgan des nervus octavus. Wiesbaden, Germany: Betgmann; 1892.

16 DiZio P, Lackner JR, Evanoff JN. The influence of gravitoinertial force level on oculomotor and perceptual responses to Coriolis, cross-coupling stimulation. Aviat Space Environ Med 1987;58(Suppl 9):A218-23.

17 Clarke AH, Teiwes W, Scherer H. Videooculography - an alternative method for measurement of three dimensional eye movements. In: Schmidt R, Zambarbieri A, editors. Oculomotor control and cognitive processes. Amsterdam (NL): Elsevier; 1991. pp. 431-43.

18 NATO Standardization Agency - Military Committee Air Standardization Board. STANAG 3114 AMD: aeromedical training of flight personnel. Eighth Edition. 2006.

19 Guedry FE, Rupert AH, McGrath BJ, et al. The dynamics of spatial orientation during complex and changing linear and angular motion. J Vestib Res 1992;2:259-83.
20 Panichi R, Occhigrossi C, Ferraresi A, et al. Adaptive changes in the perception of fast and slow movement at different head positions. Aerosp Med Hum Perf 2017;88:463-8. https://doi.org/10.3357/ AMHP.4595.2017.

21 Pettorossi VE, Panichi R, Botti FM, et al. Prolonged asymmetric vestibular stimulation induces opposite, long term effects on self-motion perception and ocular responses. J Physiol 2013;591:1907-20. https://doi.org/10.1113/jphysiol.2012.241182.

22 Takahashi M, Watanuki K, Ikeda T. Sensation and action during active and passive movement. Acta Otolaryngol (Stockh) 1999;119:121-5. https://doi.org/10.1080/00016489950181486.

23 McGrath BJ, Guedry FE, Oman CM, et al. Vestibulo-ocular response of human subjects seated in a pivoting support system during 3 Gz centrifuge stimulation. J Vestib Res 1995;5:331-47.

24 Gibb R, Ercoline WR, Scharff L. Spatial disorientation: decades of pilot fatalities. Aviat Space Environ Med 2011;82:717-24.

25 Lucertini M, Lugli V, Casagrande M, et al. Effects of airsickness in male and female student pilots: adaptation rates and 4-year outcome. Aviat Space Environ Med 2008;79:677-84.

26 Wertheim AH. Working in a moving environment. Ergonomics 1998;41:1845-58. https://doi.org/10.1080/001401398186018.

Received: January 17, 2018 - Accepted: June 12, 2018

How to cite this article: Lucertini M, Bianca E, Marciano E, et al. Analysis of the nystagmus evoked by cross-coupled acceleration (Coriolis phenomenon). Acta Otorhinolaryngol Ital 2019;39:341-346. https://doi.org/10.14639/0392-100X-2073

Address for correspondence: Marco Lucertini, Italian Air Force - Flight Experimental Centre, Aerospace Medicine Department, Pratica di Mare AFB, 00071 Pomezia (Rome), Italy. Tel. +39 06 91292292. Fax +39 06 91292075. E-mail: marco.lucertini@am.difesa.it 